\title{
Impact of child emotional and behavioural difficulties on educational outcomes of primary school children in Ethiopia: a population-based cohort study
}

\author{
Habtamu Mekonnen ${ }^{1,2^{*}} \mathbb{D}$, Girmay Medhin ${ }^{3}$, Mark Tomlinson ${ }^{4}$, Atalay Alem ${ }^{1}$, Martin Prince ${ }^{5}$
} and Charlotte Hanlon ${ }^{1,5,6}$

\begin{abstract}
Background: The relationship between child emotional and behavioural difficulties (EBD) and educational outcomes has not been investigated in prospective, community studies from low-income countries.

Methods: The association between child EBD symptoms and educational outcomes was examined in an ongoing cohort of 2090 mother-child dyads. Child EBD was measured when the mean age of children was 6.5 years, SD 0.04 (T0) and 8.4, SD 0.5 years (T1) using the Strength and Difficulties Questionnaire (SDQ). Educational outcomes were obtained from maternal report (drop-out) at $\mathrm{T1}$ and from school records at when the mean age of the children was 9.3 (SD 0.5) years (T2).

Result: After adjusting for potential confounders, child EBD symptoms at T1 were associated significantly with school absenteeism at T2: SDQ total score: Risk Ratio (RR) 1.01; 95\% confidence interval (CI) 1.01, 1.02; SDQ high score ( $\geq 14$ ) RR 1.36; $95 \% \mathrm{Cl} 1.24,1.48$; emotional subscale RR 1.03; $95 \% \mathrm{Cl} 1.01,1.04$; hyperactivity subscale RR 1.03; $95 \% \mathrm{Cl} 1.02$, 1.04 and peer problems subscale (RR 1.02; $95 \% \mathrm{Cl} 1.00,1.04)$. High SDQ $(\beta=-2.89 ; 95 \% \mathrm{Cl}-5.73,-0.06)$ and the conduct problems sub-scale $(\beta=-0.57 ; 95 \% \mathrm{Cl}-1.02,-0.12)$ had a significant negative association with academic achievement. There was no significant association between child EBD and school drop-out.
\end{abstract}

Conclusion: Prospective associations were found between child EBD symptoms and increased school absenteeism and lower academic achievement, suggesting the need for child mental health to be considered in interventions targeting improvement of school attendance and academic achievement in low-income countries.

Keywords: Child education, Absenteeism, Child emotional and behavioral difficulty, Child mental health, Cohort study, Sub-saharan Africa

\section{Background}

Early experiences play an important role in the later life of a child, including their educational success $[1,2]$. One crucial, but often overlooked, aspect of holistic child

*Correspondence: mhkurmane@gmail.com

${ }^{1}$ Department of Psychiatry, School of Medicine, College of Health Sciences, Addis Ababa University, Addis Ababa, Ethiopia

Full list of author information is available at the end of the article development is the mental health of the child. In studies from high income countries, child emotional and behavioural disorder (EBD) symptoms are associated with poorer social adaptation [3], compromised physical wellbeing, functional impairment and worse educational outcomes [4,5]. The fourth United Nations Sustainable Development Goal (SDG) aims for inclusive and quality education for all children [6], an aspiration unlikely to be

c) The Author(s) 2020. This article is licensed under a Creative Commons Attribution 4.0 International License, which permits use, sharing, adaptation, distribution and reproduction in any medium or format, as long as you give appropriate credit to the original author(s) and the source, provide a link to the Creative Commons licence, and indicate if changes were made. The images or other third party material in this article are included in the article's Creative Commons licence, unless indicated otherwise in a credit line to the material. If material is not included in the article's Creative Commons licence and your intended use is not permitted by statutory regulation or exceeds the permitted use, you will need to obtain permission directly from the copyright holder. To view a copy of this licence, visit http://creativeco mmons.org/licenses/by/4.0/. The Creative Commons Public Domain Dedication waiver (http://creativecommons.org/publicdomain/ zero/1.0/) applies to the data made available in this article, unless otherwise stated in a credit line to the data. 
achieved without due attention being given to child mental health.

Most studies from LMICs have focused on physical rather than mental health in relation to child educational outcomes $[7,8]$. We identified just one prospective study examining the impact of child EBD on educational outcomes, from Chile, an upper middle income country [9]. In studies from Nigeria [10], Pakistan [11] and Sri Lanka [12], child EBD symptoms were associated with retrospectively-ascertained educational outcomes, but the direction of the association could not be examined. To the best of our knowledge, there have been no prospective studies examining the association between child EBD and education outcomes from a low income country, where the impact of poverty on school attendance and academic achievement may overwhelm any contribution of child EBD symptoms.

In this study, we examined prospectively the association between child EBD symptoms and educational outcomes across two waves of a population-based cohort study in rural Ethiopia. We hypothesised that children with symptoms of EBD at pre- and early school age would be at increased risk of school absenteeism, drop-out and poorer academic achievement over 2 years of follow-up.

\section{Methodology}

\section{Study design}

The study was an extension of a population-based birth cohort, the child outcomes in relation to maternal mental illness in Ethiopia (C-MaMiE) study [13]. For the current analysis, three contiguous birth cohorts were included: the original C-MaMiE cohort, cohort A (born in the preceding 12 months) and cohort B (born in the following 12 months). At assessment time-point 0 (T0), children were all aged 6.5 years (SD 0.04) and then followed up at two further assessment time-points ( $\mathrm{T} 1$ and $\mathrm{T} 2$ ) for an average total period of 2.2 to 3.5 years, depending upon the birth cohort. The prospective relationship between the primary exposure and outcomes was assessed separately for two waves of the cohort: from T0 to T1 (maternal report of drop-out) and from T1 to T2 (school records of drop-out, absenteeism and achievement).

\section{Study setting}

The C-MaMiE study is located within the Health and Demographic Surveillance Site (HDSS) of the Butajira Rural Health programme, established in 1986 [14]. The Butajira HDSS includes nine rural administrative subdistricts of different ecological zones and one urban subdistrict in Butajira Town. Butajira is a predominantly rural area found in the Gurage Zone of the Southern Nations, Nationalities and Peoples' Region (SNNPR) of Ethiopia, $135 \mathrm{~km}$ away from the capital city, Addis Ababa.
The Zone is characterised by high population density with substantial ethnic and linguistic diversity. The local economy is based on mixed farming of cash crops (khat and chilli peppers) and staples (maize and "false banana" or Ensete ventricosun).

\section{Educational context}

In Ethiopia there is no school fee for governmental schools; however, parents are expected to cover costs for school uniform, exercise books and food [15]. In the study area, less than $0.3 \%$ of the study children attend private schools. The country has no standardized measure of school readiness but depends on self-reported age of 7 years. Primary education has two cycles; basic (grades 1-4) and general (grades 5-8) between the ages 7 and 14 years [15]. Coverage of primary school was estimated to be $85.5 \%$, with $10.1 \%$ drop-out overall, but higher drop-out in grade one (16.8\%) and $6.7 \%$ grade repetition in 2015/2016 [16]. Except for two national examinations at the completion of grades 10 and 12, and one regional examination at completion of grade 8 , the academic performance of students is assessed by the class teacher using non-standardized tests.

\section{Study participants}

The original C-MaMiE cohort was established between July 2005 and February 2006 in the Butajira HDSS [13]. At recruitment, inclusion criteria for the women were: age between 15 and 49 years, ability to speak Amharic, resident of the HDSS and in the third trimester of pregnancy. Fewer than $3 \%$ of eligible women were excluded at recruitment because of lack of fluency in Amharic language. A total of 1065 out of 1234 eligible women (86.3\%) were recruited and followed to date. When the C-MaMiE children were aged 6.5 years, the cohort size was augmented using the HDSS to identify cohort A $(n=543$; $94.9 \%$ of eligible) and cohort B ( $n=717 ; 92.8 \%$ of eligible) with application of identical inclusion criteria.

\section{Assessment time-points}

Exposures assessed at T0 (2012/2013 academic year) and T1 (2013/2014 academic year).

Outcomes assessed at T1 and T2 (2014/2015 academic year) at a mean age of 9.3 (SD 0.5) years. See Additional file 1 for a graphical depiction of the cohort waves and mean age for each cohort.

\section{Measures \\ Outcomes}

Absenteeism The total number of days of absence was obtained from the daily school attendance record at $\mathrm{T} 2$.

School drop-out This was operationalised as the proportion of students who had enrolled at the beginning of 
the academic year (September) but who had dropped out of school before the end of the academic year (June) and obtained from maternal report at T1 and from school records at T2. Presumed reasons for drop-out at T1 were also obtained from mothers. Children who drop out of school at T1 can be re-enroled and, therefore, drop-out again at $\mathrm{T} 2$.

Academic achievement The averaged grade point over two semesters of the Ethiopian school year was measured at T2. The class teacher grading of academic achievement is non-standardised and incorporates mastery of content, class participation and interaction, conduct, homework, progress over time and school attendance.

\section{Primary exposure}

Child EBD was measured at T0 and $\mathrm{T} 1$ using the brief screening, parent-report version of the Strengths and Difficulties Questionnaire (SDQ) for emotional and behavioural difficulties in children and adolescents aged 4 to 16 years [17]. An approved Amharic version of the SDQ is available [18]. Within the C-MaMiE cohort, the SDQ has been found to have construct and convergent validity when used as a continuous scale [19]. In keeping with the recommendation of the developer, we applied a score of 14 and above to indicate high emotional and behavioural symptoms, but we were not able to relate this to mental health problems as the criterion validity of the SDQ against clinical diagnoses has not been established in Ethiopia.

\section{Potential confounding factors}

All potential confounders were assessed at the time-point preceding the outcome measure ( $\mathrm{T} 0$ for $\mathrm{T} 1$ and $\mathrm{T} 1$ for T2).

Maternal common mental disorder was measured using the World Health Organization (WHO) 20-item version of the Self-Reporting Questionnaire (SRQ-20) [20] which has been validated in this setting [13].

Stressful life events over the preceding 6 months were measured using an adapted version of the List of Threatening Experiences [21].

Socio-economic status (SES) was measured using selfreport of house roof composition (corrugated iron vs. thatched), the experience of hunger in the preceding month, and the existence of emergency resources for times of crisis.

Paternal substance use report of the frequency of alcohol or khat use by the father was obtained from maternal self-report.

Child nutritional status height was assessed by project data collectors using a portable stadiometer with a movable head piece for height. Using the World Health Organization (WHO) reference population [22], height-for-age z scores were calculated with the WHO Anthro software [23]. Although weight was also assessed, height-for-age and weight-for-age were collinear. As height-for-age is a cumulative indicator of nutritional status [24], the heightfor-age z scores were preferred for the analysis.

Demographic characteristics age of the mother, marital status, literacy level, birth order and sex of the child were obtained from self-report of the mother.

\section{Data management}

Data collection procedures interviews with the women and anthropometric measures of the child were carried out in the woman's home, or in the surrounding area, according to their preference. Child anthropometric measures were also conducted in school when convenient. The project data collectors, who had all completed secondary school education and above, were given 3 days of intensive refresher training on the administration of instruments. The questionnaires were piloted before commencing data collection and discrepancies in ratings were discussed to ensure that the data collectors had a common understanding.

Maintaining data quality supervisors monitored data quality and identified missing data in the field. Random quality checks were performed on a sample of assessments. Data were double entered with EpiData [25] by project data clerks on the day of data collection, where possible.

\section{Statistical analyses}

Stata software version 12 [26] was used for the analysis. The analysis was hypothesis-driven with potential confounders specified a priori. SDQ total score, SDQ high $(\geq 14)$ score and total scores of SDQ sub-scales were the primary exposures. Logistic regression was used for school drop-out (binary outcomes), zero-inflated poisson regression was used to model absenteeism (count variable, with excess zeroes), and linear regression was used to model academic achievement (continuous outcome, normally distributed). Estimates of association were presented with their respective $95 \%$ confidence intervals. An exploratory analysis was carried out to examine whether there was effect modification by cohort between the primary exposure and outcomes.

\section{Results}

At T0 and T1, 2090 and 1957 mother-child dyads, respectively, were available for follow-up. See Fig. 1.

There was no difference between those remaining in the cohort and who were lost to follow-up from T0 to T1 and from T0 to T2 in terms of maternal CMD, parental literacy, socioeconomic status, EBD symptoms and birth order. However, those lost to follow-up were more likely 


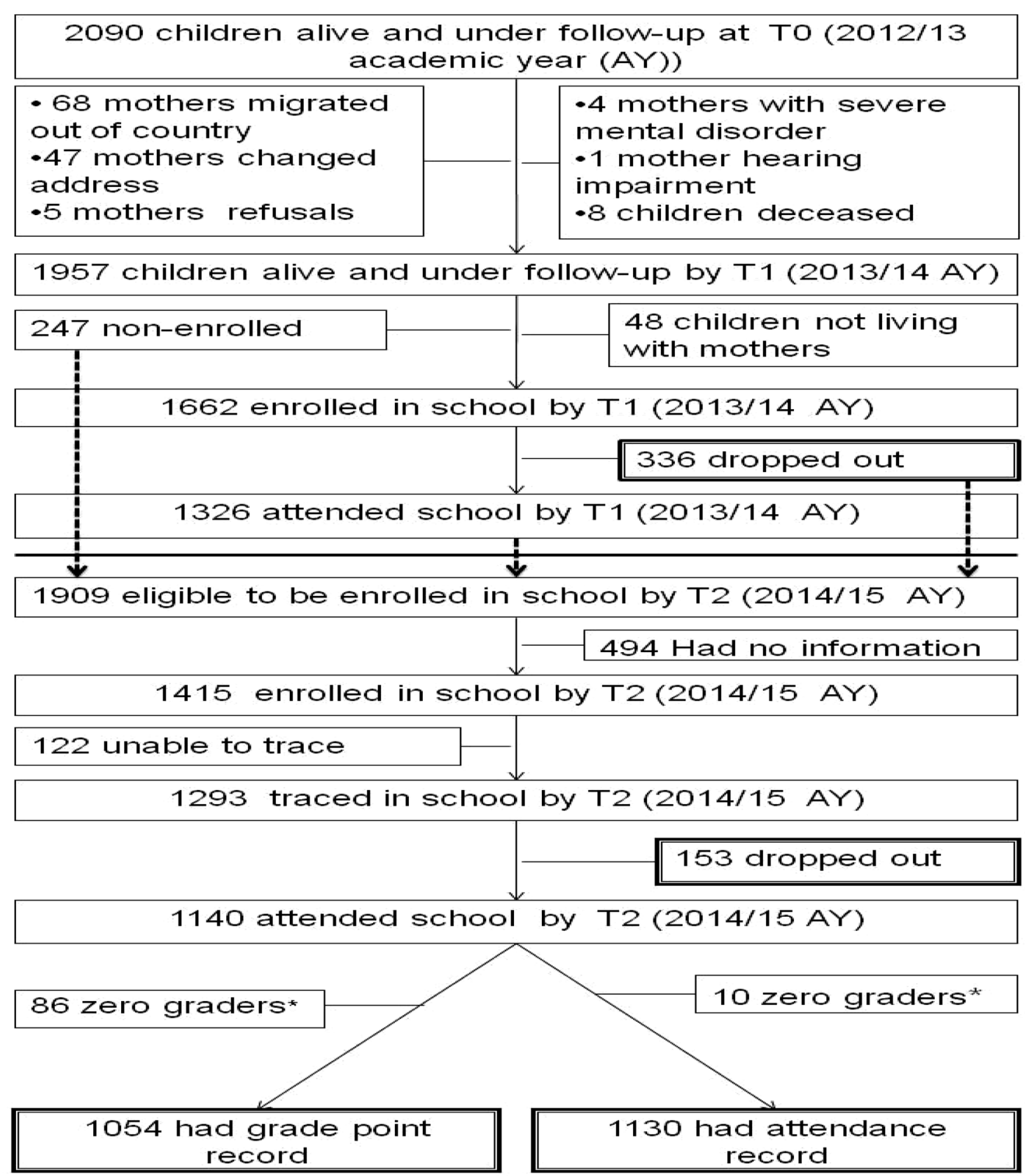

Fig. 1 Follow-up chart. *Had no attendance and academic records, ${ }^{\top 0}$ assessment time-point $0,{ }^{\top 1}$ assessment time-point $1,{ }^{\top 2}$ assessment time-point 2

to be boys and less likely to have emergency resources from T0 to T1 and those lost to follow-up were more likely to be stunted, more likely to have thatched roof cover and less likely to have emergency resources from T0 to T2. See Additional files 2 and 3.

The percentage of children who scored 14 and above on the SDQ was $7.2 \%(n=151)$ at T0 and $5.9 \%(n=112)$ at T1. At T0, 58.3\% of high scorers were boys, which increased to $73.2 \%$ at $\mathrm{T} 1$. Boys scored higher than girls on all sub-scales of the SDQ except on the emotional sub-scale. In both boys and girls, symptoms of hyperactivity problems were most frequently noted, followed by peer relationship problems and conduct problems (see Additional file 4 for the graphic depiction).

School drop-out was $20.2 \%(\mathrm{n}=336)$ at $\mathrm{T} 1$ and $11.8 \%$ $(\mathrm{n}=153)$ at T2. At T2, the median number of days of 
absence was 5 (interquartile range 2-11), with 191 (17.0\%) children having no days of absence. The mean average grade point was 62.5 out of 100 (SD 9.2). See Tables 1 and 2 .

The reasons given by mothers for their children dropping out of school at T1 are presented in Additional file 5, and included being bullied, disciplinary action and child school refusal. In the fully adjusted models, child EBD symptoms were not significantly associated with school drop-out at either T1 or T2. The total score on the SDQ (Risk Ratio $=1.01$, CI $(1.01,1.02), \mathrm{p}=<0.001)$, emotional (Risk Ratio $=1.03$, CI $(1.01,1.04, \mathrm{p}=0.001)$, hyperactivity (Risk Ratio $=1.03, \mathrm{CI}(1.02,1.04, \mathrm{p}<0.001)$, and peer relationship (Risk Ratio $=1.02$, CI $(1.00,1.04, p=0.022)$, sub-scales measured at $\mathrm{T} 1$ were significantly associated with absenteeism at T2. High SDQ $(\beta$ coefficient $=-2.90$ $(-5.76,-0.05) \mathrm{p}=0.046)$, and conduct problem ( $\beta$ coefficient $=-0.55$, CI $(-1.01,-0.10) \mathrm{p}=0.017)$, sub-scale scores at $\mathrm{T} 1$ was significantly inversely associated with academic achievement at T2 (Table 3).

There was some evidence of modification of the associations between EBD and absenteeism by cohort (tests for interaction: C-MaMiE cohort $\mathrm{p}=0.034$, cohort $\mathrm{B}$ $\mathrm{p}=0.001)$. In the C-MaMiE cohort $(\mathrm{n}=464)$ the associations between child EBD and absenteeism remained significant. In cohort A $(n=293)$, with the older children, the association became non-significant, and in cohort B $(n=367)$, with the younger children, the direction of association was reversed. See Additional file 6 for the full stratified analysis.

\section{Discussion}

In this prospective cohort study from a rural population in Ethiopia, child EBD symptoms were associated significantly with child school absenteeism. High SDQ score and the SDQ conduct difficulty sub-scale were significantly associated with poor academic achievement. There was no association between child EBD symptoms and school drop-out.

To the best of our knowledge, this is the first study from sub-Saharan Africa to investigate the association between pre- and early school age child EBD symptoms and subsequent educational outcomes. Our study benefited from a large sample size, prospective study design, high follow-up rate and the use of culturally validated measures. There were also limitations. The measures of child EBD and maternal mental health were screening tools and do not represent a clinical level of difficulty. The measurement of child EBD symptoms relied upon the report of the mother. It would have been preferable to combine this with reports from the teachers. However, class sizes are large (average 63 per class in SNNPR) [16]. Therefore, teachers may not know individual children well enough to identify symptoms of EBD, except those behaviours leading to disciplinary challenges. We assessed academic achievement using non-standardized, composite assessments by individual teachers. Although this approach could have increased measurement error, it may be more valid than narrowly focused assessments of content mastery. As attendance is a component of the rating of academic achievement, there could have been overlap in these outcome measures. Routinely recorded attendance data to identify absenteeism may underestimate the true number of missed days. The indicators of socioeconomic status may not have been adequate, leading to the possibility of residual confounding. In addition, we may not have adjusted adequately for child physical ill-health, although we included anthropometric measures which are a proxy indicator of cumulative exposure to illness.

Our finding of an association between child EBD symptoms and subsequent absenteeism is in keeping with the large prospective study from Chile [9] and a retrospective study from Sri Lanka, where child mental health problems at the time of assessment were associated with absenteeism (dichotomised as $>20 \%$ of school days missed) in the preceding year [12]. In our study, the association between child EBD and absenteeism remained significant after adjusting for several indicators of social adversity, which are known to be strong predictors of school absenteeism and drop-out in rural low-income country settings [27]. There was some evidence of effect modification of the association between child EBD and absenteeism in our analyses, although the sub-samples were small. It is possible that the importance of child EBD symptoms in relation to absenteeism varies with the developmental stage of the child and the prevalence of other risk factors for absenteeism. We were not, however, able to investigate the possible mechanisms through which EBD symptoms are associated with absenteeism. In high-income countries, child EBD symptoms may negatively affect peer interactions, attitudes towards school, self-worth, and the responses of teachers and peers to the child [4]. In turn, this may negatively affect regular attendance. In low-income countries such as Ethiopia, where there is limited recognition of child EBD symptoms and scarce child mental health services these potential pathways from EBD to absenteeism may be amplified.

Absenteeism in a rural low-income country setting is likely to lead to poorer academic achievement due to the limited opportunities to catch up through independent study, given the lack of educational resources at home. Absenteeism is also on the pathway towards full drop-out from school [28]. However, in contrast to findings from Chile [9] and studies from high-income countries, e.g. [29], we did not find a significant association between child EBD symptoms and school drop-out. An 
Table 1 Summary of participants in relation to educational outcome at T1

\begin{tabular}{|c|c|c|c|}
\hline \multirow[t]{3}{*}{ Characteristics at TO } & \multicolumn{2}{|c|}{ Child school drop-out at T1 $(n=1662)$} & \multirow[t]{3}{*}{ MV } \\
\hline & Dropped out N (\%) & Attending $\mathrm{N}(\%)$ & \\
\hline & $336(20.2)$ & $1326(79.8)$ & \\
\hline \multicolumn{4}{|l|}{ Child EBD } \\
\hline High SDQ ( $\geq 14)$ & $21(6.3)$ & $95(7.2)$ & \multirow[t]{2}{*}{14} \\
\hline Low SDQ $(<14)$ & $311(93.7)$ & $1222(92.8)$ & \\
\hline Mean maternal age in years (standard deviation) & $34.0(6.0)$ & $33.0(6.0)$ & 5 \\
\hline \multicolumn{4}{|l|}{ Maternal literacy } \\
\hline Non-literate & $307(91.6)$ & $1100(83.3)$ & \multirow[t]{2}{*}{6} \\
\hline Literate & $28(8.4)$ & $221(16.7)$ & \\
\hline \multicolumn{4}{|l|}{ Paternal literacy } \\
\hline Non-literate & $148(46.7)$ & $423(33.3)$ & \multirow[t]{2}{*}{75} \\
\hline Literate & $169(53.3)$ & $847(66.7)$ & \\
\hline \multicolumn{4}{|l|}{ Marital status } \\
\hline Monogamous & $263(78.5)$ & $1089(82.4)$ & \multirow[t]{3}{*}{6} \\
\hline Polygamous & $54(16.1)$ & $182(13.8)$ & \\
\hline Divorced, widowed, separated & $18(5.4)$ & $50(3.8)$ & \\
\hline \multicolumn{4}{|l|}{ Had hunger in preceding month } \\
\hline Yes & $42(12.5)$ & $80(6.1)$ & \multirow[t]{2}{*}{6} \\
\hline No & $293(87.5)$ & $1241(93.9)$ & \\
\hline \multicolumn{4}{|l|}{ Had emergency resources } \\
\hline No & $164(48.9)$ & $485(36.7)$ & \multirow[t]{2}{*}{6} \\
\hline Yes & $171(51.1)$ & $836(63.3)$ & \\
\hline \multicolumn{4}{|l|}{ Roof material } \\
\hline Thatched roof & $242(72.2)$ & $809(61.2)$ & \multirow[t]{2}{*}{6} \\
\hline Corrugated iron & $93(27.8)$ & $512(38.8)$ & \\
\hline \multicolumn{4}{|l|}{ Father's khat use } \\
\hline Weekly & $264(83.5)$ & $976(76.9)$ & \multirow[t]{2}{*}{77} \\
\hline Less than weekly & $52(16.5)$ & $293(23.1)$ & \\
\hline \multicolumn{4}{|l|}{ Father's alcohol use } \\
\hline Weekly & $55(17.4)$ & $185(14.6)$ & \multirow[t]{2}{*}{77} \\
\hline Less than weekly & $261(82.6)$ & $1084(85.4)$ & \\
\hline \multicolumn{4}{|l|}{ Negative life event in the last 6 months } \\
\hline No life event & $272(81.9)$ & $1065(81.2)$ & \multirow[t]{3}{*}{18} \\
\hline 1 life event & $48(14.5)$ & $184(14.0)$ & \\
\hline 2 or more & $12(3.6)$ & $63(4.8)$ & \\
\hline Maternal mental health & & & \\
\hline SRQ score $\geq 6$ & $19(5.7)$ & $54(4.1)$ & 6 \\
\hline SRQ score $<6$ & $316(94.3)$ & $1267(95.9)$ & \\
\hline Childbirth order & & & \\
\hline First & $26(7.7)$ & $212(16.0)$ & 0 \\
\hline Middle or last & $310(92.3)$ & $1114(84.0)$ & \\
\hline Sex of the child & & & \\
\hline Boy & $201(59.8)$ & $6705(0.6)$ & 0 \\
\hline Girl & $135(40.2)$ & $654(49.4)$ & \\
\hline Child age mean standard deviations & $6.5(0.04)$ & $6.5(0.04)$ & 0 \\
\hline Child nutritional status (height for age) & & & \\
\hline Stunted & $111(33.4)$ & $297(46.0)$ & 15 \\
\hline Non-stunted & $221(66.6)$ & $1018(77.4)$ & \\
\hline
\end{tabular}

SDQ Strength and Difficulty Questionnaire, SRQ Self Reporting Questionnaire, MV missing value, T0 assessment time-point 0, T1 assessment time-point 1 
Table 2 Summary of participants in relation to educational outcomes at T2

\begin{tabular}{|c|c|c|c|c|c|c|c|}
\hline \multirow[t]{5}{*}{ Characteristics at T1 } & \multicolumn{7}{|c|}{ Outcomes measured at T2 } \\
\hline & \multicolumn{2}{|c|}{ Child school drop-out $(n=1293)$} & \multirow[t]{4}{*}{ MV } & \multirow{3}{*}{$\begin{array}{l}\text { absenteeism ( } n=1130) \\
\text { Median (25th, 75th centile) }\end{array}$} & \multirow[t]{4}{*}{ MV } & \multirow{3}{*}{$\begin{array}{l}\text { Academic } \\
\text { achievement } \\
(n=1054) \\
\text { Mean (SD) }\end{array}$} & \multirow[t]{4}{*}{ MV } \\
\hline & \multirow{3}{*}{$\begin{array}{l}\text { Dropped out } \\
\text { N (\%) } \\
153(11.8)\end{array}$} & \multirow{3}{*}{$\begin{array}{l}\text { Attending } \\
\mathrm{N}(\%) \\
1140(88.2)\end{array}$} & & & & & \\
\hline & & & & & & & \\
\hline & & & & $5(2,11)$ & & $62.5(9.2)$ & \\
\hline \multicolumn{8}{|l|}{ Child EBD } \\
\hline SDQ score $(\geq 14)$ & $11(7.4)$ & $58(5.2)$ & \multirow[t]{2}{*}{18} & $5(3,12)$ & \multirow[t]{2}{*}{13} & $60.2(6.3)$ & \multirow[t]{2}{*}{9} \\
\hline SDQ score $<14$ & $138(92.6)$ & $1068(94.8)$ & & $4(2,11)$ & & $62.6(9.3)$ & \\
\hline $\begin{array}{l}\text { Mean maternal age in years (standard } \\
\text { deviation) }\end{array}$ & $33.9(5.51)$ & $33.5(5.45)$ & 7 & & 2 & & 6 \\
\hline \multicolumn{8}{|l|}{ Maternal literacy } \\
\hline Non-literate & $142(93.4)$ & $997(88.0)$ & \multirow[t]{2}{*}{8} & $5(2,12)$ & \multirow[t]{2}{*}{6} & $62.5(9.3)$ & \multirow[t]{2}{*}{6} \\
\hline Literate & $10(6.6)$ & $136(12.0)$ & & $3(3,5)$ & & $62.3(8.6)$ & \\
\hline \multicolumn{8}{|l|}{ Paternal literacy } \\
\hline Non-literate & $62(42.5)$ & $400(36.8)$ & \multirow[t]{2}{*}{60} & $6(3,14)$ & 52 & $61.3(9.2)$ & 50 \\
\hline Literate & $84(57.5)$ & $687(63.2)$ & & $4(1,9)$ & & $63.2(9.2)$ & \\
\hline Marital status & & & & & & & \\
\hline Monogamous & $116(76.8)$ & $908(81.0)$ & 21 & $5(2,12)$ & 18 & $62.8(9.3)$ & 17 \\
\hline Polygamous & $28(18.5)$ & $160(14.3)$ & & $4(2,9)$ & & $61.1(8.9)$ & \\
\hline Divorced, widowed, separated & $7(4.6)$ & $53(4.7)$ & & $4(1,6)$ & & $62.1(8.1)$ & \\
\hline Had hunger in preceding month & & & & & & & \\
\hline Yes & $12(7.9)$ & $50(4.4)$ & 9 & $5(2,11)$ & 7 & $62.1(7.8)$ & 7 \\
\hline No & $140(92.1)$ & $1082(95.6)$ & & $5(2,11)$ & & $62.5(9.3)$ & \\
\hline Had emergency resource & & & & & & & \\
\hline No & $49(32.2)$ & $322(28.4)$ & 8 & $5(2,11)$ & 6 & $62.1(9.1)$ & 6 \\
\hline Yes & $103(67.8)$ & $811(71.6)$ & & $5(2,11)$ & & $62.7(9.3)$ & \\
\hline Roof material & & & & & & & \\
\hline Thatched & $94(61.8)$ & $601(53.0)$ & 8 & $6(3,14)$ & 6 & $62.8(9.7)$ & 6 \\
\hline Corrugated iron & $58(38.2)$ & $532(47.0)$ & & $3(1,8)$ & & $62.2(8.7)$ & \\
\hline Father's khat use & & & & & & & \\
\hline Weekly & $104(72.2)$ & $880(82.7)$ & 83 & $5(2,12)$ & 75 & $62.3(9.2)$ & 58 \\
\hline Less than weekly & $40(27.8)$ & $184(17.3)$ & & $3.5(0,8)$ & & $63.6(9.5)$ & \\
\hline Father's alcohol use & & & & & & & \\
\hline Weekly & $30(20.8)$ & $173(16.2)$ & 85 & $3.5(1,7)$ & 73 & $64.6(9.4)$ & 60 \\
\hline Less than weekly & $114(79.2)$ & $893(83.8)$ & & $5(2,12)$ & & $62.2(9.2)$ & \\
\hline Negative life event in the last 6 months & & & & & & & \\
\hline No life event & $108(71.1)$ & $860(75.9)$ & 8 & $5(2,12)$ & 6 & $62.5(9.1)$ & 6 \\
\hline 1 life event & $31(20.4)$ & $196(17.3)$ & & $4(2,9)$ & & $62.8(9.8)$ & \\
\hline 2 or more & $13(8.6)$ & $77(6.8)$ & & $3(2,8)$ & & $61.2(8.2)$ & \\
\hline Maternal CMD & & & & & & & \\
\hline SRQ score $\geq 6$ & $20(13.2)$ & $117(10.3)$ & 8 & $5(2,11)$ & 6 & $62.0(9.5)$ & 6 \\
\hline SRQ score $<6$ & $132(86.8)$ & $1016(89.7)$ & & $5(2,11)$ & & $62.6(9.2)$ & \\
\hline Childbirth order & & & & & & & \\
\hline First & $16(10.5)$ & $156(13.8)$ & 0 & $4.5(2,14)$ & 0 & $62.8(8.9)$ & 0 \\
\hline Middle or last & $136(89.5)$ & $977(86.2)$ & & $5(2,11)$ & & $62.5(9.3)$ & \\
\hline Sex of the child & & & & & & & \\
\hline Boy & $85(55.6)$ & $590(52.0)$ & 0 & $5(2,12)$ & 0 & $62.6(9.2)$ & 0 \\
\hline Girl & $68(44.4)$ & $544(48.0)$ & & $4(2,10)$ & & $62.4(9.2)$ & \\
\hline Child nutritional status & & & & & & & \\
\hline Stunted & $53(34.9)$ & $244(21.6)$ & 11 & $5(2,10)$ & 9 & $62.3(9.5)$ & 9 \\
\hline Non-stunted & $99(65.10$ & $886(78.4)$ & & $4.5(2,11)$ & & $62.6(9.2)$ & \\
\hline
\end{tabular}

SDQ Strength and Difficulty Questionnaire, SRQ Self Reporting Questionnaire, MV missing value, $T 1$ assessment time-point 1, $T 2$ assessment time-point 2 
Table 3 Impact of child emotional and behavioural difficulties on educational outcomes

\begin{tabular}{|c|c|c|c|c|c|}
\hline \multirow[t]{2}{*}{ Exposures } & \multirow[t]{2}{*}{ Models } & \multirow{2}{*}{$\begin{array}{l}\text { Child EBD at T0 } \\
\text { Drop-out at } \mathrm{T} 1 \\
(\mathrm{n}=1662) \\
\text { Odds ratio }(95 \% \\
\text { confidence interval; } \\
\mathrm{Cl})\end{array}$} & \multicolumn{3}{|l|}{ Child EBD at $\mathrm{T} 1$} \\
\hline & & & $\begin{array}{l}\text { Drop-out at } \mathrm{T} 2(\mathrm{n}=1293) \\
\text { Odds ratio }(95 \% \mathrm{Cl})\end{array}$ & $\begin{array}{l}\text { Absenteeism } \\
\text { at T2 }(n=1130) \\
\text { Risk ratio }(95 \% \mathrm{Cl})\end{array}$ & $\begin{array}{l}\text { Academic achievement } \\
\text { at T2 }(n=1054) \\
\beta \text { coefficient }(95 \% \mathrm{Cl})\end{array}$ \\
\hline \multicolumn{6}{|l|}{ SDQ sub-scales (total scores) } \\
\hline \multirow[t]{2}{*}{ Emotional problem } & Crude & $1.05(0.96,1.15)$ & $1.06(0.95,1.19)$ & $1.02(1.00,1.03)^{* *}$ & $-0.11(-0.51,0.30)$ \\
\hline & Adjusted $^{\mathrm{a}}$ & $1.03(0.93,1.13)$ & $1.01(0.89,1.14)$ & $1.03(1.01,1.04)^{* *}$ & $-0.13(-0.55,0.31)$ \\
\hline \multirow[t]{2}{*}{ Conduct difficulty } & Crude & $1.10(1.00,1.20)^{* *}$ & $1.05(0.93,1.18)$ & $0.99(0.97,1.00)$ & $-0.41(-0.82,0.00)^{* *}$ \\
\hline & Adjusted $^{\mathrm{a}}$ & $1.05(0.95,1.16)$ & $1.01(0.88,1.16)$ & $1.01(0.99,1.02)$ & $-0.55(-1.01,-0.10)^{* *}$ \\
\hline \multirow[t]{2}{*}{ Hyperactivity problem } & Crude & $1.05(0.98,1.12)$ & $0.99(0.91,1.09)$ & $1.02(1.00,1.03)^{* *}$ & $-0.15(-0.46,0.16)$ \\
\hline & Adjusted $^{\mathrm{a}}$ & $1.02(0.94,1.10)$ & $0.98(0.88,1.109)$ & $1.03(1.02,1.04)^{* *}$ & $-0.11(-0.45,0.23)$ \\
\hline \multirow[t]{2}{*}{ Peer relationship problem } & Crude & $1.03(0.94,1.12)$ & $0.99(0.86,1.14)$ & $1.00(0.98,1.02)$ & $-0.21(-0.67,0.25)$ \\
\hline & Adjusted $^{a}$ & $1.02(0.93,1.12)$ & $0.97(0.83,1.13)$ & $1.02(1.00,1.04)^{* *}$ & $-0.12(-0.63,0.39)$ \\
\hline \multicolumn{6}{|l|}{ SDQ full scale } \\
\hline \multirow[t]{2}{*}{ Total score } & Crude & $1.01(0.98,1.04)$ & $1.01(0.97,1.05)$ & $1.00(1.00,1.01)$ & $-0.09(-0.22,0.04)$ \\
\hline & Adjusted $^{\mathrm{a}}$ & $1.01(0.97,1.03)$ & $0.99(0.95,1.04)$ & $1.01(1.01,1.02)^{* *}$ & $-0.10(-0.24,0.04)$ \\
\hline \multirow[t]{2}{*}{ High score $(\geq 14)$} & Crude & $0.87(0.53,1.41)$ & $1.48(0.75,2.86)$ & $1.23(1.13,1.34)^{* *}$ & $-2.44(-5.04,-0.16)$ \\
\hline & Adjusted $^{\mathrm{a}}$ & $0.71(0.41,1.23)$ & $1.17(0.56,2.44)$ & $1.36(1.24,1.48)^{* *}$ & $-2.90(-5.76,-0.05)^{* *}$ \\
\hline
\end{tabular}

T0 assessment time-point 0, T1 assessment time-point 1, T2 assessment time-point 2

** The association is significant at $95 \% \mathrm{Cl}$ and $\mathrm{P}$ value less than 0.05

a Maternal age, marital status, maternal and paternal level of literacy, SES, paternal substance use, negative life event, maternal CMD, child sex, birth order and nutritional status

association between child EBD and drop-out may have not been detected in our study because of the time for progression from absenteeism to drop-out and limited statistical power to detect an association. Nonetheless, the reasons given by women for their child dropping out of school at T1 included being bullied, disciplinary action and child school refusal, all of which suggest that child EBD symptoms may have had a role to play in school drop-out for some children.

The significant negative association of both high SDQ score and the SDQ conduct problems sub-scale with academic achievement in our study is also in line with the Chilean study [9], as well as the retrospective study from Nigeria [10] and a cross sectional study from Pakistan [11] and a review of studies from high-income countries [5]. We found different patterns of association between SDQ sub-scales and educational outcomes; while the conduct sub-scale was associated with academic achievement, emotional, peer relationship and hyperactivity sub-scales were associated with absenteeism. Conduct problems may be more easily recognised by teachers than internalising problems due to large class sizes and the nature of the problems. This may negatively affect the teacher's subjective evaluation of academic performance which is based on a composite of participation, attendance and interaction. Emotional and peer relationship symptoms may play more of a role in absenteeism than academic achievement, which is also indicated by the parental report of bullying and school refusal as reasons for school drop-out. However, the interconnection between absenteeism, academic achievement and dropout requires more detailed future study.

Child absenteeism is a barrier to the achievement of 'inclusive and quality education for all children', as articulated in the United Nations Sustainable Development Goal number 4. Recent recommendations from the Disease Control Priorities group for 'best practice' interventions at the community level for mental and neurological disorders in LMICs [30] included: socioemotional learning, mental health awareness, detection of mental and neurological disorders in schools, early child enrichment or preschool educational and parenting programme for children. In Chile, providing students with school-based mental health services and skills for life [9] was associated with improvement in attendance and achievement. Earlier studies from Ethiopia have found food insecurity [27] and maternal mental health [31] to be important determinants of school attendance. Multi-faceted interventions may be required, which provide both social and psychological support to families of children who are absent from school, coupled with efforts to increase teacher 
and community awareness about mental health. Current efforts to scale-up mental health care in Ethiopia by integrating mental health into community health extension worker prevention and promotion activities, as well as into primary care services, [32] provide an important opportunity to improve child mental health and potentially impact on educational outcomes.

\section{Conclusions}

In this study from rural Ethiopia, child emotional and behavioural difficulty symptoms were associated prospectively with absenteeism and negatively with academic achievement. We plan to follow-up the cohort to look at the changing patterns of EBD symptoms and longer-term impacts on standardised national examination performance. Interventions targeting reduction of school absenteeism and improvement of academic achievement need to attend to the mental health of the child.

\section{Supplementary information}

Supplementary information accompanies this paper at https://doi. org/10.1186/s13034-020-00326-6.

Additional file 1. Assessments time-points and outcome measures.

Additional file 2 . Difference beteen those children who remain and lost to follow-up from T0 to T1 $(n=2090)$.

Additional file 3. Difference beteen those children who do and do not have educational information at T1 $(n=1957)$.

Additional file 4. Graph of SDQ item frequency by sex of the child at T0.

Additional file 5. Maternal report of reasons for school drop-out at T1.

Additional file 6. Impact of child emotional and behavioural difficulties on absenteeism by cohort.

\begin{abstract}
Abbreviations
C-MaMiE: Child outcomes in relation to maternal mental illness in Ethiopia; EBD: Emotional and behavioural difficulty; HDSS: Health and Demographic Surveillance Site; LMICs: Low and middle income countries; RR: Risk ratio; SDG: Sustainable development goal (SDG); SDQ: Strength and Difficulties Questionnaire; SNNRP: Southern Nations, Nationalities and Peoples' Region; SRQ-20: Self-Reporting Questionnaire; WHO: World Health Organization.
\end{abstract}

\section{Acknowledgements}

We would like to thank the women who took part in the study, at the expense of their energy and time to complete interviews, and to the staff in the schools who facilitated the data collection process. Our thanks also go to the project data collectors and staff of the C-MaMiE project in Butajira.

\begin{abstract}
Authors' information
$\mathrm{HM}, \mathrm{CH}$ and MP formulated the research question, $\mathrm{HM}, \mathrm{CH}$ and MP designed the study, with input from AA, GM and MT. HM led the conduct of the study with in-country supervision from $\mathrm{CH}$ and GM. HM led the data analysis, with input from $\mathrm{CH}, \mathrm{MP}$ and $\mathrm{GM}$. HM drafted the article, with contributions from $\mathrm{CH}, \mathrm{MP}, \mathrm{GM}, \mathrm{AA}$ and MT. All authors read and approved the final manuscript.
\end{abstract}

\section{Funding}

The study was funded by the Wellcome Trust (Project Grant: 093559).

\section{Availability of data and materials}

The data are being used for a PhD student (HM) for his thesis and are not, therefore, available at the present time to the general public. The data may be requested from the corresponding author for verification of the analyses in this paper.

\section{Ethics approval and consent to participate}

The study was approved by Addis Ababa University College of Health Sciences Institutional Review Board (IRB) (approval number 082/13/psy) and the Research Ethics Committee of Kings College London (approval number PNM/13/14-92). The mother provided informed consent for her own and her child's participation in the study as well to access school records of the child. Assent was obtained from the children for the anthropometric assessment. Women with suicidal ideation were referred to Butajira hospital for treatment. As there are no normative data for rural Ethiopian children to determine abnormal scores on the SDQ, referral was not made on the basis of SDQ scores, but a referral to psychiatric services in Addis Ababa was made if the family expressed concern about the child's mental health.

\section{Consent for publication \\ Not applicable.}

\section{Competing interests}

The authors declare that they have no competing interests.

\section{Author details}

${ }^{1}$ Department of Psychiatry, School of Medicine, College of Health Sciences, Addis Ababa University, Addis Ababa, Ethiopia. ${ }^{2}$ Department of Psychology, College of Education and Behavioural Sciences, Jimma University, Jimma, Ethiopia. ${ }^{3}$ Aklilu-Lemma Institute of Pathobiology, Addis Ababa University, Addis Ababa, Ethiopia. ${ }^{4}$ Department of Psychology, Stellenbosch University, Stellenbosch, South Africa. ${ }^{5}$ Health Service and Population Research Department, Centre for Global Mental Health, Institute of Psychiatry, Psychology and Neuroscience, King's College London, London, UK. ${ }^{6}$ Centre for Innovative Drug Development and Therapeutic Trials for Africa (CDT-Africa), College of Health Sciences, Addis Ababa University, Addis Ababa, Ethiopia.

Received: 28 June 2019 Accepted: 5 May 2020

Published online: 16 May 2020

\section{References}

1. Walker SP, Wachs TD, Gardner JM, Lozoff B, Wasserman GA, Pollitt E, et al. Child development: risk factors for adverse outcomes in developing countries. Lancet. 2007:369(9556):145-57 (Epub 2007/01/16.eng).

2. Chartier MJ, Walker JR, Naimark B. Separate and cumulative effects of adverse childhood experiences in predicting adult health and health care utilization. Child Abuse Negl. 2010;34(6):454-64.

3. Farmer TW, Irvin MJ, Motoca LM, Leung M-C, Hutchins BC, Brooks DS, et al. Externalizing and internalizing behavior problems, peer affiliations, and bullying involvement across the transition to middle school. J Emot Behav Disord. 2015;23(1):3-16.

4. Veldman K, Bültmann U, Stewart RE, Ormel J, Verhulst FC, Reijneveld SA. Mental health problems and educational attainment in adolescence: 9-year follow-up of the TRAILS study. PLOS ONE. 2014;9(7):e101751.

5. De Lugt J. Academic achievement of students with emotional and behavioural disorders: a review of the research. Except Educ Int. 2007;17(3):111-36.

6. Nam UV. Transforming our world: the 2030 agenda for sustainable development. 2015.

7. King N, Dewey C, Borish D. Determinants of primary school nonenrollment and absenteeism: results from a retrospective, convergent mixed methods, cohort study in rural Western Kenya. PLoS ONE. 2015;10(9):e0138362.

8. Al-Dawood KM. Schoolboys with bronchial asthma in Al-Khobar city, Saudi Arabia: are they at increased risk of school absenteeism? J Asthma. 2002:39:413-20.

9. Murphy JM, Guzmán J, McCarthy AE, Squicciarini AM, George M, Canenguez KM, et al. Mental health predicts better academic outcomes: a 
longitudinal study of elementary school students in Chile. Child Psychiatry Hum Dev. 2015;46(2):245-56.

10. Akpan M, Ojinnaka NC, Ekanem EE. Academic performance of school children with behavioural disorders in Uyo, Nigeria. Afr Health Sci. 2010;10(2):154-8

11. Soomro NH, Clarbour J. Emotional behaviour and academic achievement in middle school children. Pak J Soc Clin Psychol. 2012;10(1):10-6.

12. Siriwardhana C, Pannala G, Siribaddana S, Sumathipala A, Stewart R. Impact of exposure to conflict, tsunami and mental disorders on school absenteeism: findings from a national sample of Sri Lankan children aged 12-17 years. BMC Public Health. 2013;13(1):560.

13. Hanlon C, Medhin G, Alem A, Araya M, Abdulahi A, Hugh M, et al. Detecting perinatal common mental disorders in Ethiopia: validation of the self-reporting questionnaire and Edinburgh Postnatal Depression Scale. J Affect Disord. 2008;108(2008):251-62.

14. Berhane Y, Wall S, Kebede D, Emmelin A, Enquselassie F, Byass P, et al. Establishing an epidemiological field laboratory in rural areas: the Butajira Rural Health Programme 1987-99. Ethiop J Health Dev. 1999;13(Special):1-47.

15. Ministry of Education. The education and training policy and its implementation, Ethiopia. 2002.

16. Ministry of Education FDGoE. Education Statistics 2007 E.C. (2014/2015). Addis Ababa, Ethiopia: MoE, EMIS and ICT Directorate. 2016.

17. Goodman R. The extended version of the strengths and difficulties questionnaire as a guide to child psychiatric caseness and consequent burden. J Child Psychol Psychiatry. 1999;40(5):791-9.

18. Goodman, Robert, 2002. 2013. http://www.sdqinfo.com.

19. Servili C. Maternal mental health as a predictor of adverse behavioural and emotional outcomes in pre-school age children: a population-based birth cohort study in rural Ethiopia. Unpublished PhD Dissertation. 2014.

20. Beusenberg M, Orley J. A user's guide to the Self Reporting Questionnaire (SRQ). Geneva: World Health Organization; 1994.

21. Brugha TS, Bebbington PE, Tennant C, Hurry J. The list of threatening experiences: a subset of 12 life event categories with considerable longterm contextual threat. Psychol Med. 1985;15:189-94.

22. WHO. Physical status: the use and interpretation of anthropometry. Geneva: World Health Organization; 1995. Technical report series No. 854. 1995.
23. WHO. Anthro version 3.2.2. 2011. http://www.who.int/childgrowth/softw are/en/.

24. Keller W, Fillmore CM. Prevalence of protein-energy malnutrition. World Health Star Q. 1983;36:129.

25. Epidata. Epidata (Version 3): a comprehensive tool for validated entry and documentation of data. [program]. 3rd ed. Odense: The Epidata Association. 2003.

26. Stata C. Stata statistical software release 12. College Station: Stata Corporation; 2007.

27. Belachew T, Hadley C, Lindstrom D, Gebremariam A, Lachat C, Kolsteren P. Food insecurity, school absenteeism and educational attainment of adolescents in Jimma Zone Southwest Ethiopia: a longitudinal study. Nutr J. 2011;10(29):2011.

28. Bruner C, Discher A, Chang H. Chronic elementary absenteeism: a problem hidden in plain sight. Research Brife. 2011.

29. Townsend L, Flisher AJ, Chikobvu P, Lombard C, King G. The relationship between bullying behaviours and high school dropout in Cape Town, South Africa. South Afr J Psychol. 2008;38(1):21-32.

30. Petersen I, Evans-Lacko S, Semrau M, Barry MM, Chisholm D, Gronholm P, et al. Promotion, prevention and protection: interventions at the population and community-levels for mental, neurological and substance use disorders in low and middle-income countries. Int J Ment Health Syst. 2016;10(30):2016

31. Mekonnen H, Medhin G, Tomlinson M, Alem A, Prince M, Hanlon C. Impact of maternal common mental disorders on child educational outcomes at 7 and 9 years: a population-based cohort study in Ethiopia. BMJ Open. 2018;8(1):e018916.

32. Fekadu A, Thornicroft G. Global mental health: perspectives from Ethiopia. Glob Health Action. 2014;7(1):25447.

\section{Publisher's Note}

Springer Nature remains neutral with regard to jurisdictional claims in published maps and institutional affiliations.
Ready to submit your research? Choose BMC and benefit from:

- fast, convenient online submission

- thorough peer review by experienced researchers in your field

- rapid publication on acceptance

- support for research data, including large and complex data types

- gold Open Access which fosters wider collaboration and increased citations

- maximum visibility for your research: over 100M website views per year

At BMC, research is always in progress.

Learn more biomedcentral.com/submissions 